\title{
REVIEWS
}

Adv Clin Exp Med 2016, 25, 3, 575-585

DOI: $10.17219 /$ acem $/ 37451$

(C) Copyright by Wroclaw Medical University

ISSN 1899-5276

Karolina Kaczor-Urbanowicz ${ }^{1}$ A-D, MaŁgorzata Zadurska ${ }^{2, \text { E, F, }}$ Ewa Czochrowska ${ }^{2, \text { E, F }}$

\section{Impacted Teeth: An Interdisciplinary Perspective}

${ }^{1}$ Hadassah School of Dental Medicine, Hebrew University of Jerusalem, Israel

${ }^{2}$ Department of Orthodontics, Medical University of Warsaw, Poland

A - research concept and design; $\mathbf{B}$ - collection and/or assembly of data; C - data analysis and interpretation;

$\mathbf{D}$ - writing the article; $\mathbf{E}$ - critical revision of the article; $\mathbf{F}$ - final approval of article

\begin{abstract}
A tooth normally erupts when half to three-quarters of its final root length has developed. Tooth impaction is usually diagnosed well after this period and is generally asymptomatic. It is principally for this reason that patients seek treatment later than optimal. Tooth impaction is a common problem in daily orthodontic practice and, in most cases, it is recognized by chance in a routine dental examination. Therefore, it is very important that dental practitioners are aware of this condition, since early detection and intervention may help to prevent many harmful complications. The treatment of impacted teeth requires multidisciplinary cooperation between orthodontists, oral surgeons and sometimes periodontists. Orthodontic treatment and surgical exposure of impacted teeth are performed in order to bring the impacted tooth into the line of the arch. The treatment is long, more complicated and challenging. This article presents an overview of the prevalence, etiology, diagnosis, treatment and complications associated with the management of impacted teeth (Adv Clin Exp Med 2016, 25, 3, 575-585).
\end{abstract}

Key words: etiology, impacted teeth, surgical techniques, orthodontic treatment, multidisciplinary treatment.

Tooth impaction is generally asymptomatic and, because of that, only a small number of patients seek treatment. In most cases, tooth impaction is recognized by chance by general dentists or orthodontists, when a patient comes to their office for a routine check-up. Therefore, it is very important to inform dental practitioners about this frequently occurring phenomenon in everyday clinical practice and to emphasize the importance of early detection and intervention to prevent possible harmful consequences [1]. Patients diagnosed with tooth impaction should be referred to an orthodontist and a dental surgeon for consultation and further treatment. The importance of an interdisciplinary approach between orthodontists, dental surgeons and sometimes periodontists regarding management of impacted teeth is crucial and should be highlighted [2]. The aim of the present article is to present the main issues regarding impacted teeth other than third molars since these are generally extracted.

\section{Definition and Prevalence}

Tooth impaction is a common dental condition ranging from $0.8-3.6 \%$ of the general population $[3,4]$. A tooth normally erupts when half to three-quarters of its final root length has developed. Impaction is usually diagnosed well after the tooth should have erupted [5]. The most commonly impacted teeth are, consecutively, third molars, maxillary canines, mandibular premolars and maxillary central incisors $[3,6,7]$.

The prevalence of third molar impaction (Fig. 1) ranges from $16.7 \%$ to $68.6 \%$ [8]. Most studies have reported no sexual predilection in third molar impaction [9]. However, some studies found a higher frequency in females than in males [10].

The prevalence of maxillary canine impaction (Fig. 1-3) ranges from $0.8-2.8 \%[7,11]$. Upper canines can be impacted palatally, buccally or in line with the dental arch. Palatal impaction is the most frequent type $[2,12]$. The ratio of palatal to buccal impaction varies from $2: 1$ [13] or $3: 1$ [14] to 


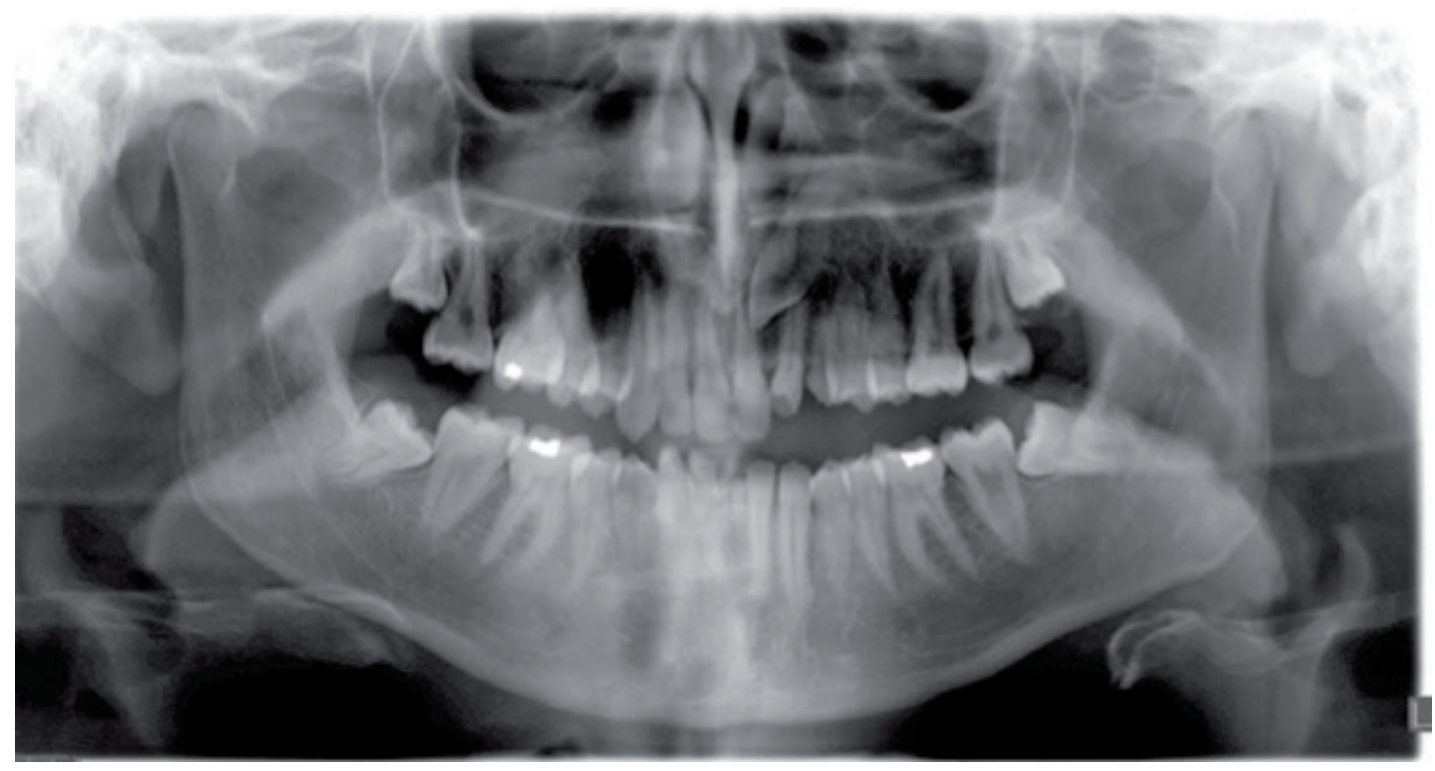

Fig. 1. 18-year old boy with impacted, transposed maxillary left canine, positioned close to the midline, and with mesially angulated, impacted teeth: 38,48 and missing two lower incisors: A - panoramic view

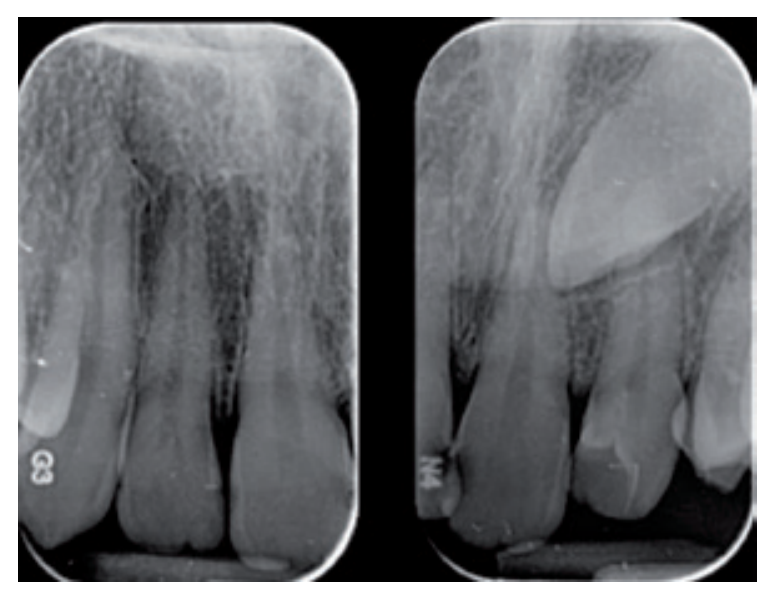

Fig. 1B. Periapical view
6.6:1 [15]. According to Ericson and Kurol, the incidence of palatally impacted canines in relation to buccally impacted canines is $85 \%$ to $15 \%$, respectively [16]. Also, various but significant differences in the occurrence of impaction between females and males have been reported, such as 2.3 to 1 (American population [6]), 2.5 to 1 (Israeli population [17]) and 3 to 1 (Welsh population [18]).

In the population of patients who are referred to regional hospitals, the prevalence of unerupted maxillary central incisors (Fig. 3-4) has been estimated as $2.6 \%$ [19]. Some studies indicate that $0.42-2.1 \%$ of patients suffer from central incisor impaction due to the presence of supernumerary teeth [20].
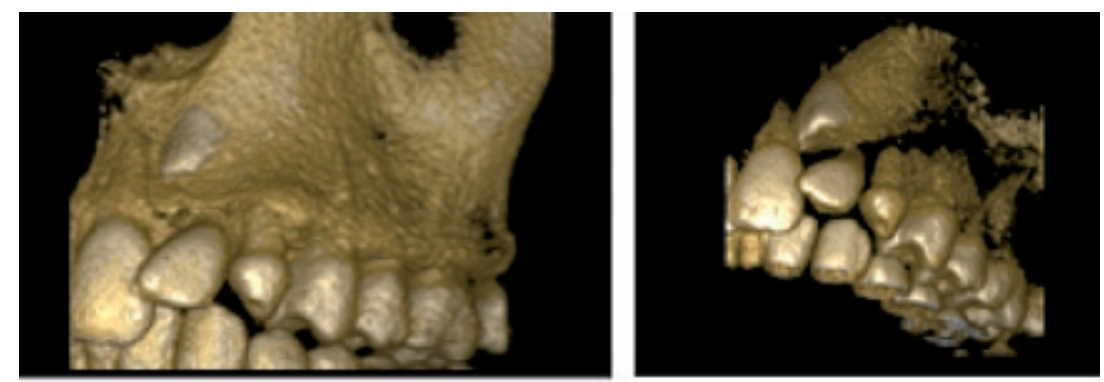

Fig. 1C. 3-dimensional CBCT, transaxial and axial views of impacted upper left cuspid
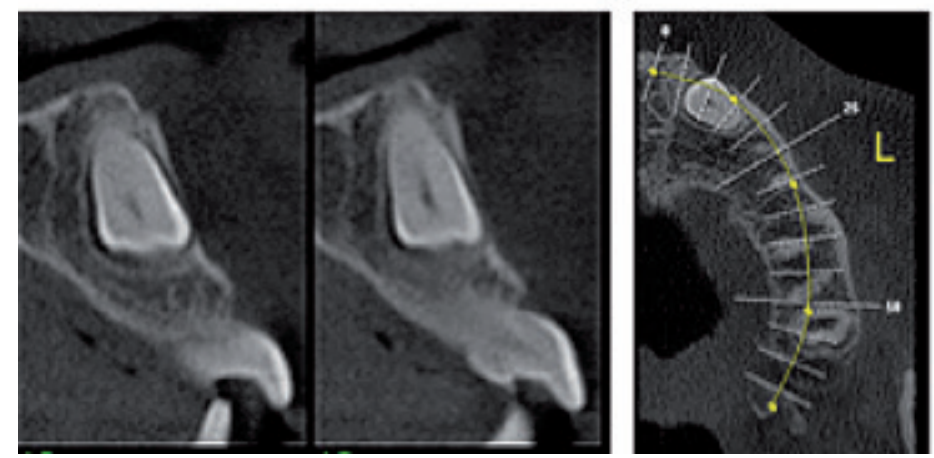


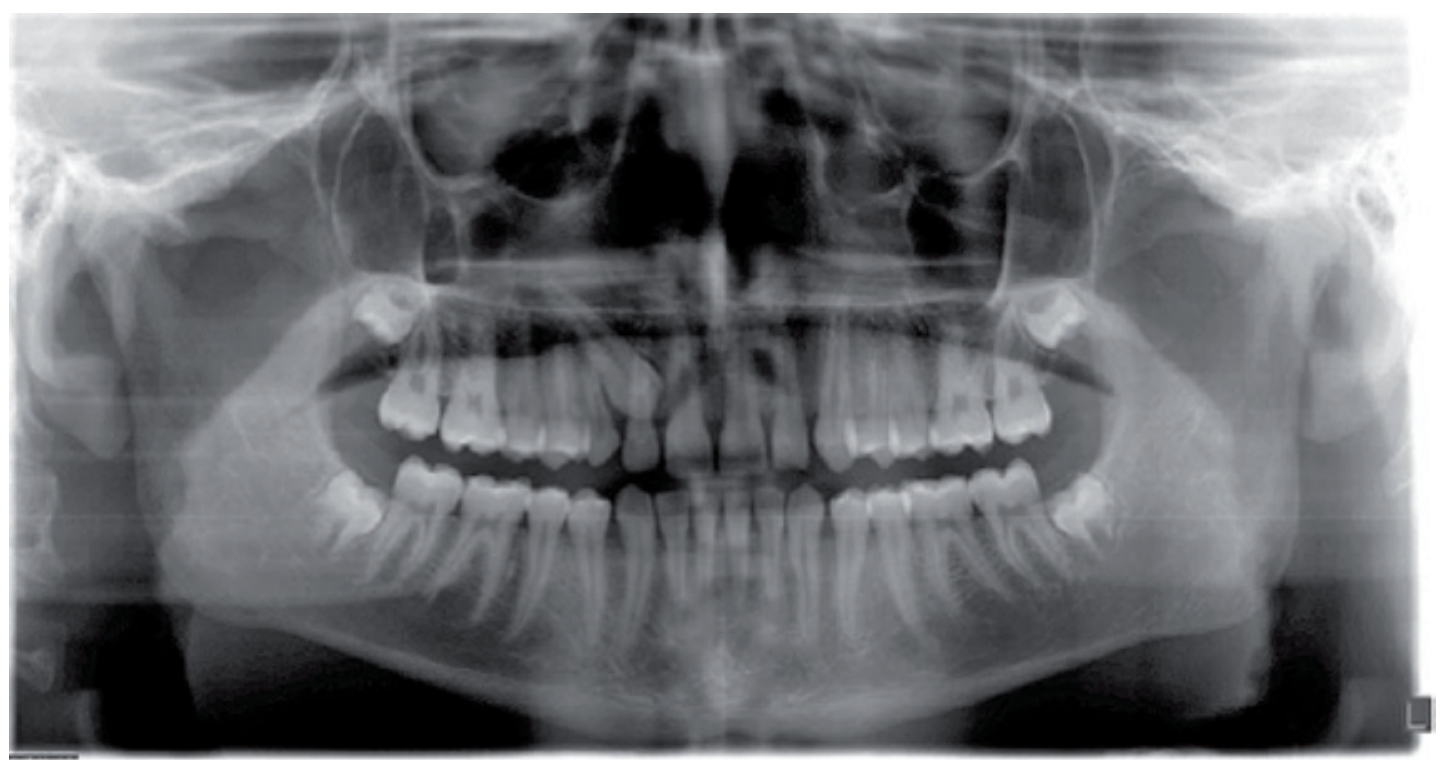

Fig. 2. 15-year old boy with palatally impacted maxillary right canine: A - panoramic view

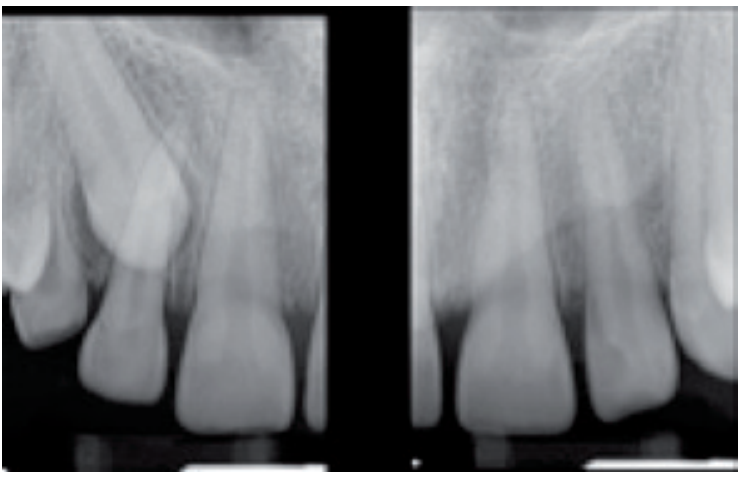

Fig. 2B. Periapical view

\section{Etiology}

The etiology of tooth impaction is multifactorial. In the literature, the most commonly reported etiological factors related to tooth impaction can be divided into three different groups: systemic, local and genetic $[1,3,21-22]$ :

\section{Systemic factors:}

1) endocrine deficiencies (e.g. hypothyroidism),

2) radiation therapy,

3) cleidocranial dysostosis,

4) amelogenesis imperfecta.
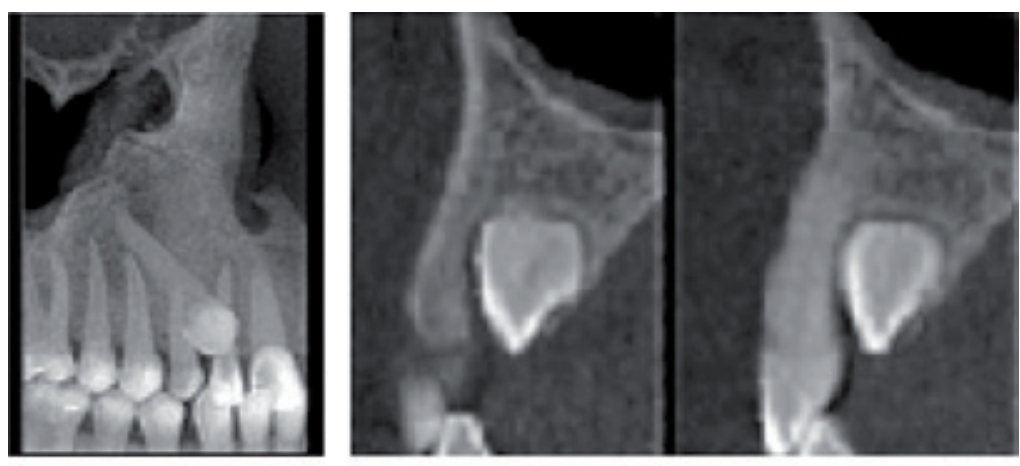

Fig. 2C. Transaxial and axial CBCT views
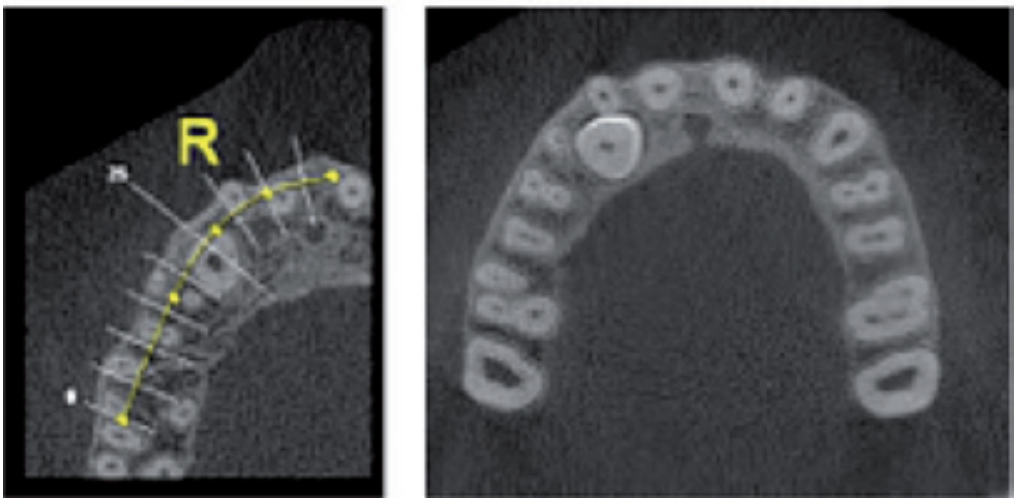

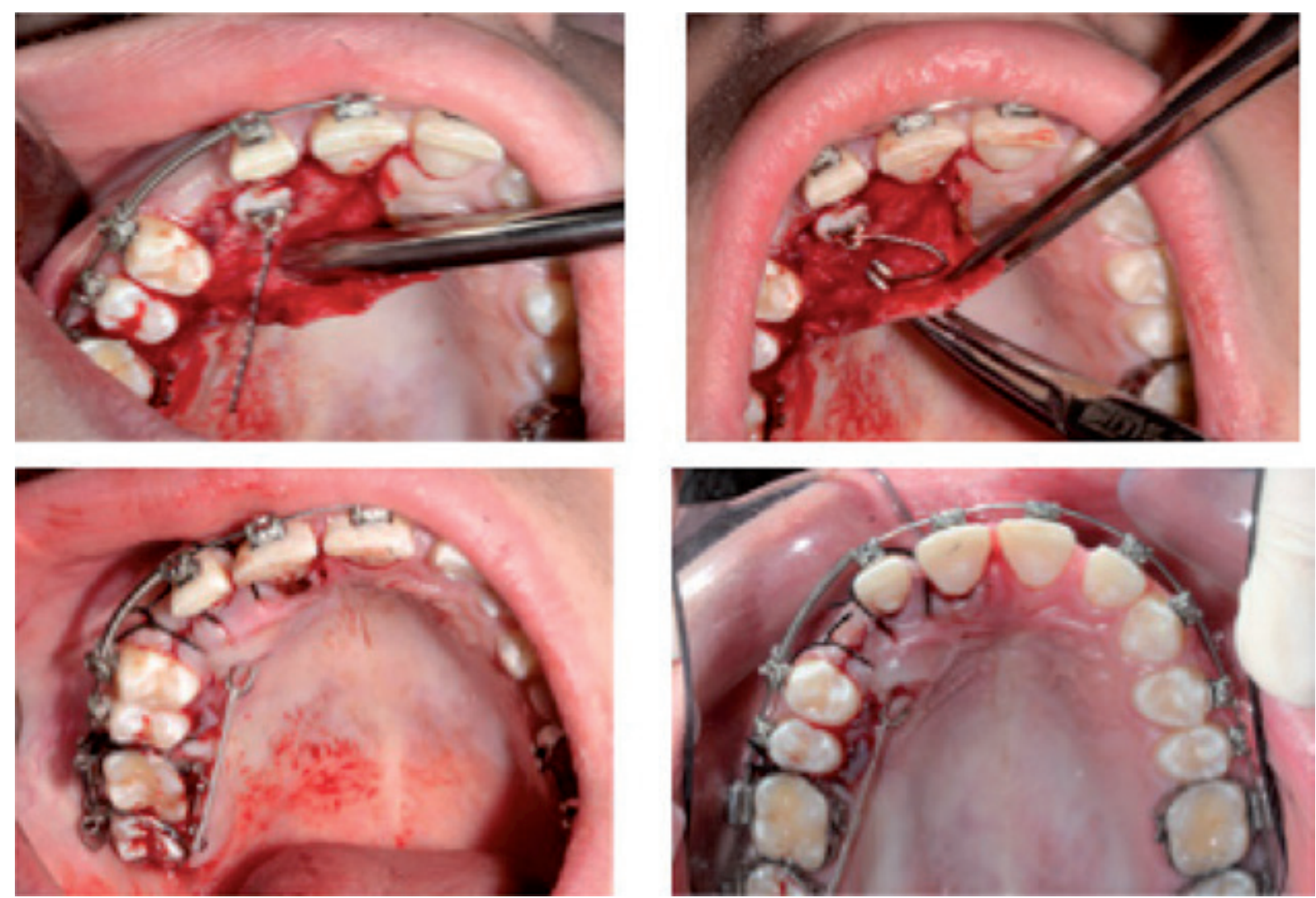

Fig. 2D. First surgical exposure (closed eruption technique) performed by Prof. Arye Shteyer
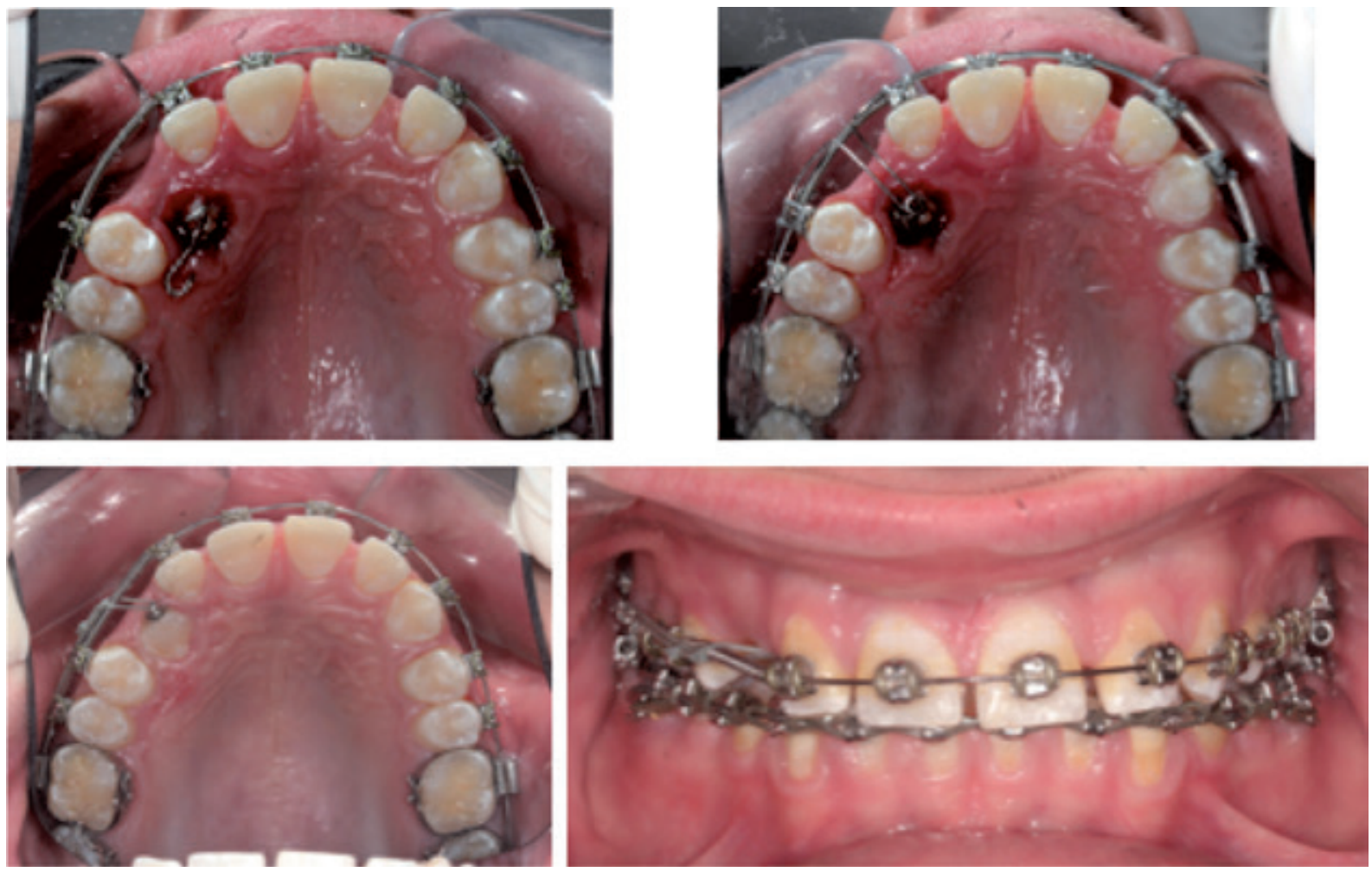

Fig. 2E. Second surgical exposure (open eruption technique) performed by Prof. Arye Shteyer

II. Local factors:

1) failure of deciduous tooth resorption,

2) premature loss of a deciduous tooth,
3) prolonged retention of a deciduous tooth,

4) abnormal eruptive path,

5) presence of a supernumerary tooth/teeth, 


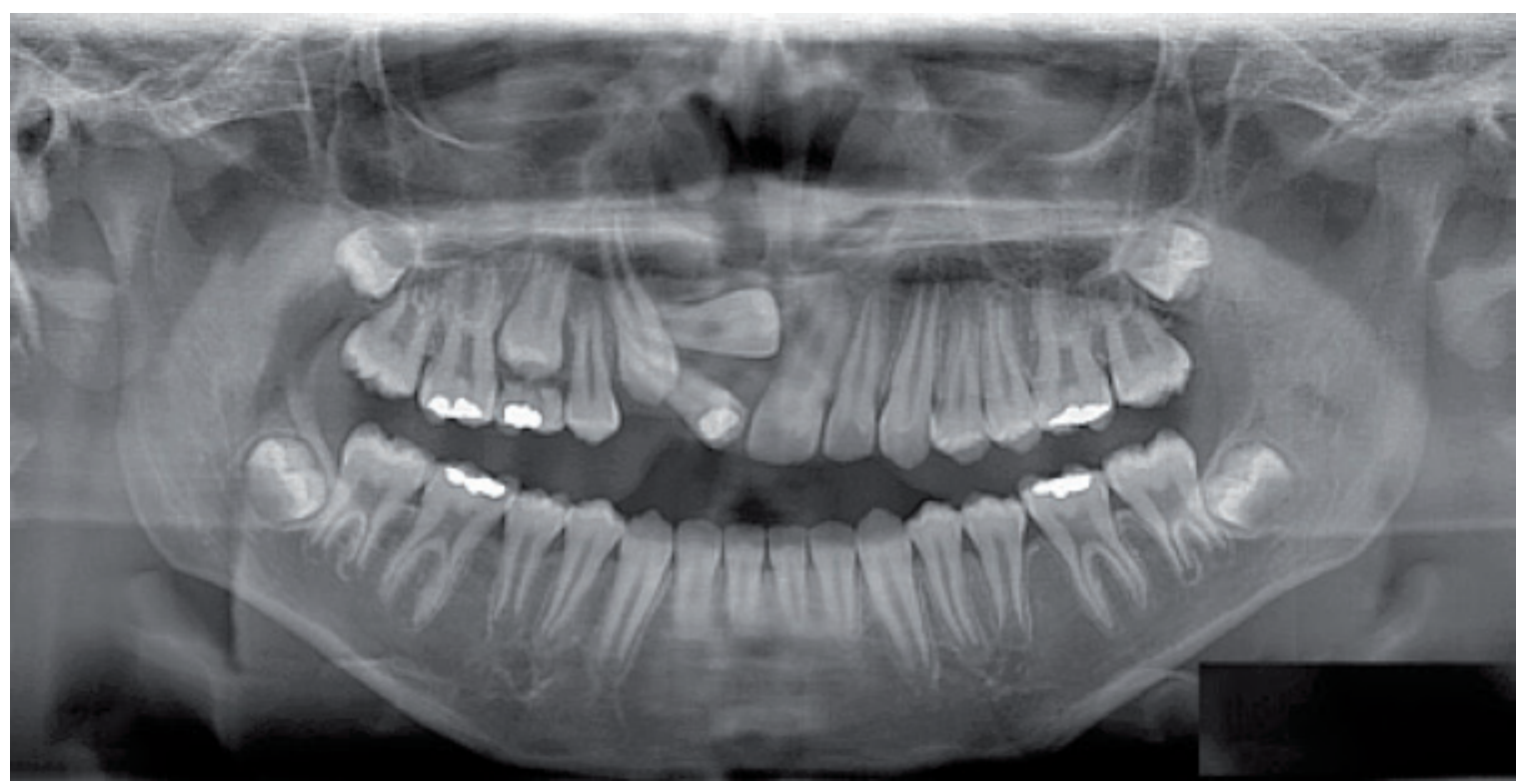

Fig. 3. 12-year old boy with 2 buccally impacted teeth: 13 and 11. After the orthodontic opening of space for impacted teeth, tooth \#13 erupted spontaneously; A - panoramic view

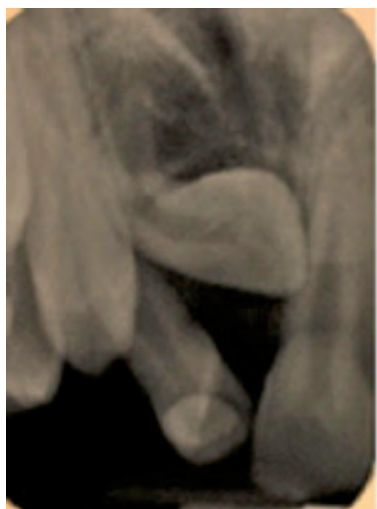

Fig. 3B. Periapical view

6) dental crowding and space loss,

7) early extraction of a deciduous tooth,

8) enlarged dental follicle/dentigerous cyst or other forms of soft tissue pathology (neoplasm),

9) thickened post-extraction or post-trauma repair of the mucosa,

10) dental trauma,

11) odontoma,

12) anomaly in the position of a tooth (e.g. tilting, displacement, transmigration),

13) ankylosis of deciduous molars,

14) root dilacerations,

15) alveolar cleft.

\section{Genetic factors:}

1) hereditary factors such as a malposed tooth germ and presence of an alveolar cleft.

\section{Third Molars}

The most common cause of impaction of the third molars (Fig. 1) is the discrepancy between jaw and tooth size, e.g. lack of space in the lower arch [23].

\section{Maxillary Canines}

There are two main theories related to the etiology of palatally impacted maxillary canines (Fig. 2), the genetic theory [24, 25] and the guidance theory $[17,26,27]$. The genetic theory declares that maxillary palatal impaction has familial and hereditary component and includes other associated dental anomalies, such as missing or small lateral incisors [24]. Additionally, impaction of upper canines is correlated with enamel hypoplasia, infraocclusion of primary molars, aplasia of second premolars and small size of maxillary upper lateral incisors [28]. According to the guidance theory, the canine erupts along the distal surface of the root of the lateral incisor, which serves as a guide. If the root of the lateral incisor is absent or malformed (peg-shaped), the canine may not erupt $[1,29]$. Palatal displacement of canines can occur when the cuspids have sufficient or even excessive space in the maxilla. In the case of buccally impacted canines, the most probable reason is dental crowding [15]. 

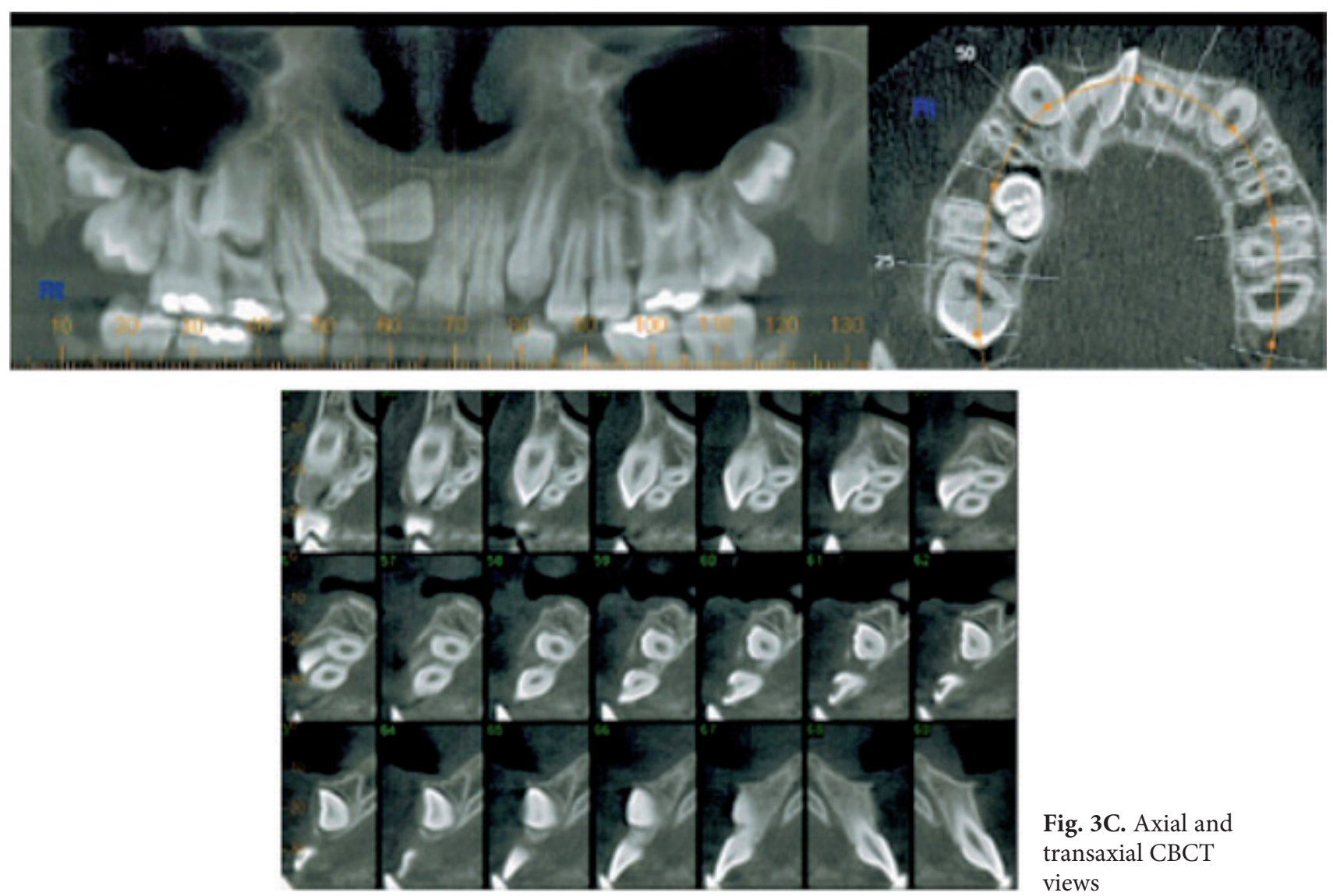

Fig. 3C. Axial and transaxial CBCT views
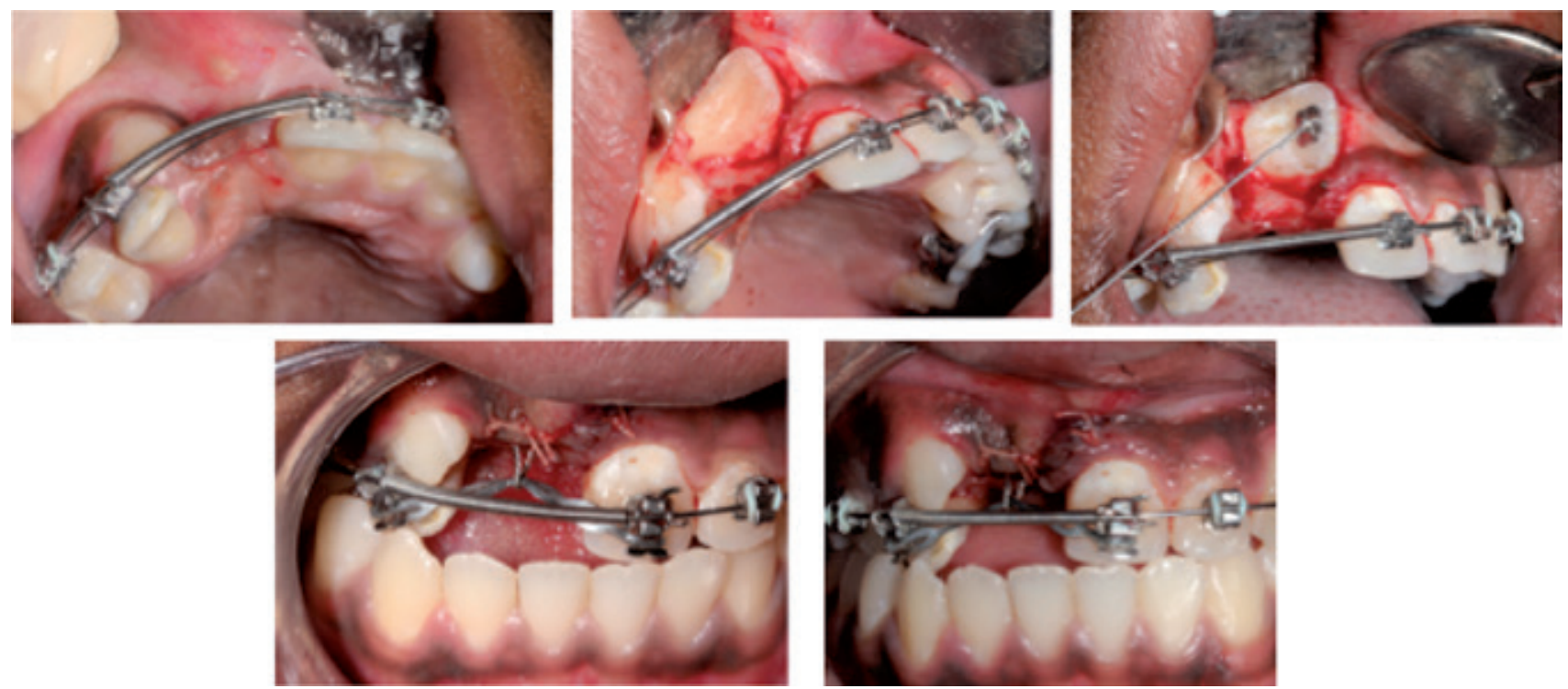

Fig. 3D. Surgical exposure of impacted right central incisor (closed eruption technique) performed by Prof. Arye Shteyer

\section{Maxillary Central Incisors}

The most common cause of impaction of the maxillary central incisor (Fig. 3-4) is the presence of a supernumerary tooth including a mesiodens $[1,30]$.

\section{Diagnosis, Timing and Prevention}

During the clinical examination, we should always suspect the impaction of a permanent tooth, when: 1) its normal time of eruption is exceeded, 2) there is insufficient space for tooth eruption, 


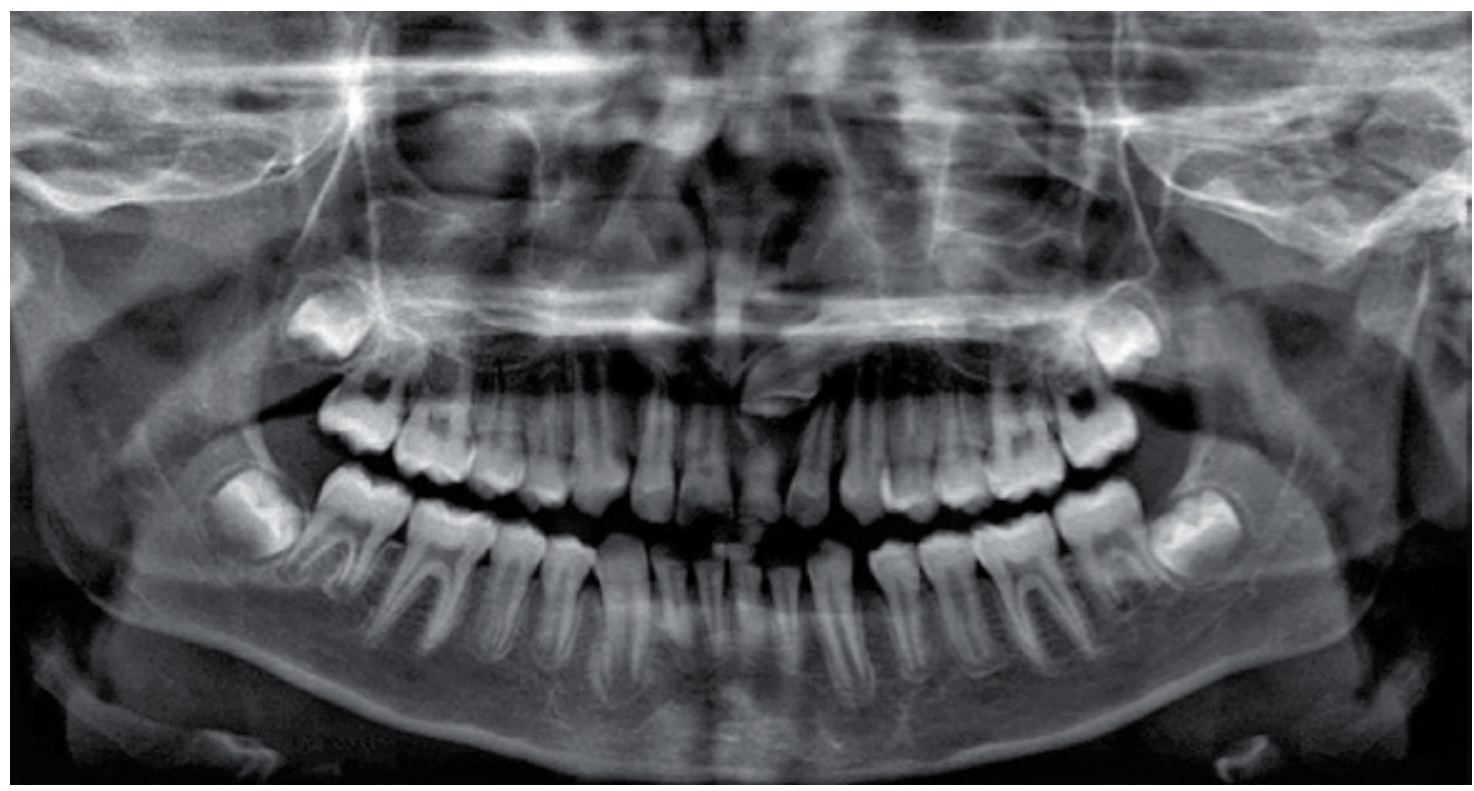

Fig. 4. 13-year old boy with impacted maxillary left central incisor; A - panoramic view

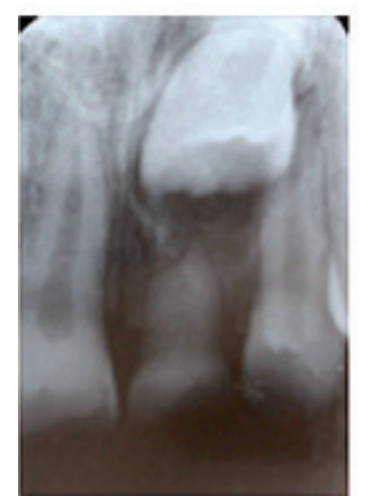

Fig. 4B. Periapical view
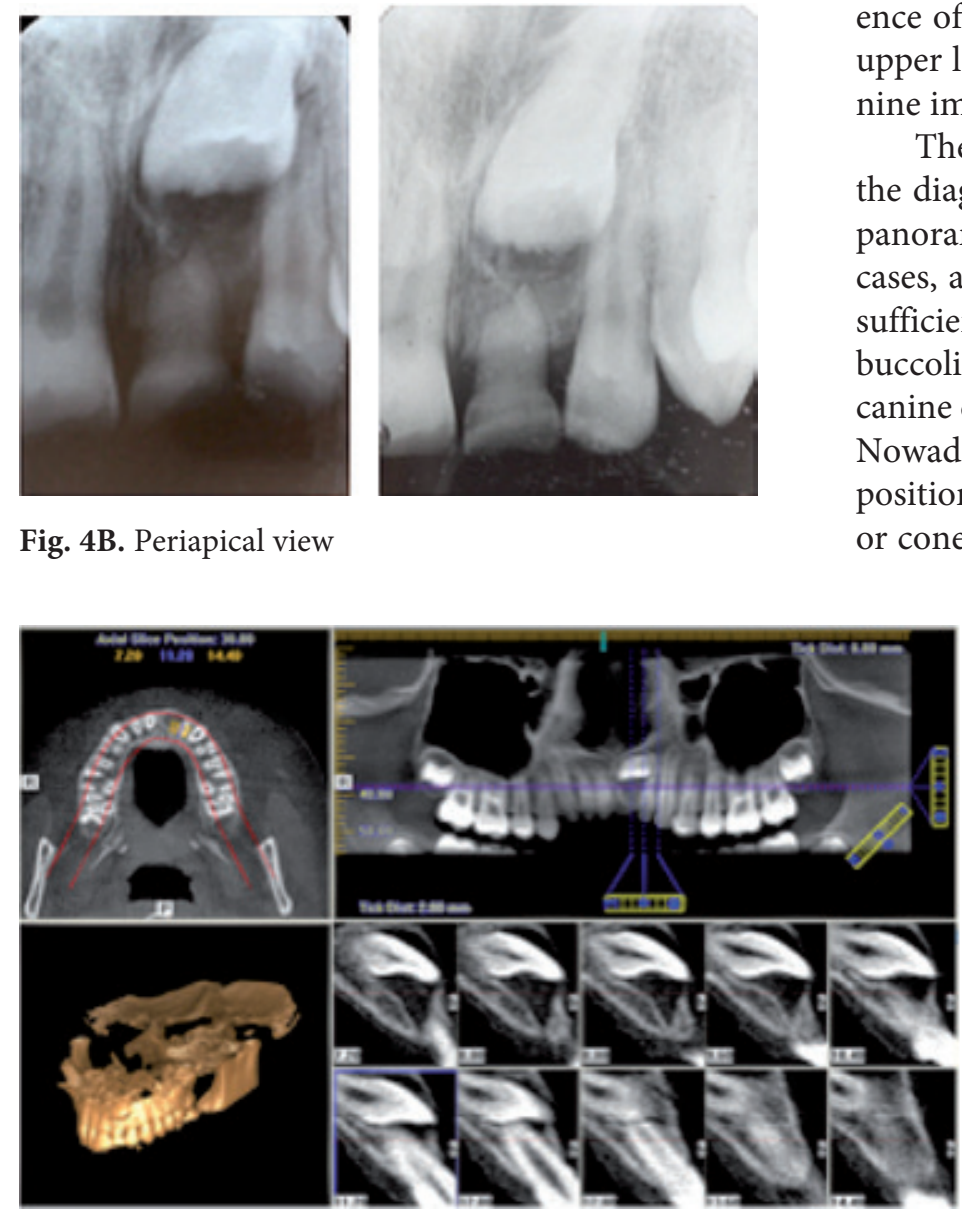

ence of congenitally missing, small or peg-shaped upper lateral incisors may also indicate palatal canine impaction $[1,17,29]$.

The most common radiographic methods in the diagnosis of tooth impaction are periapical or panoramic radiographs (OPG). However, in many cases, a diagnosis based on $2 \mathrm{D}$ radiography is not sufficient, because it is very difficult to assess the buccolingual aspects of the relation between the canine crown and the roots of the incisors $[32,33]$. Nowadays, three-dimensional diagnosis of tooth position, such as computerized tomography (CT) or cone beam computerized tomography (CBCT),

Fig. 4C. Axial and transaxial CBCT views

3) in case of the malposition or malformation of the adjacent teeth such as rotations, or 4) in case of over-retention of deciduous teeth [31]. Moreover, the upper permanent canines should be palpated buccally after the age of 10 years $[12,15]$. The pres-

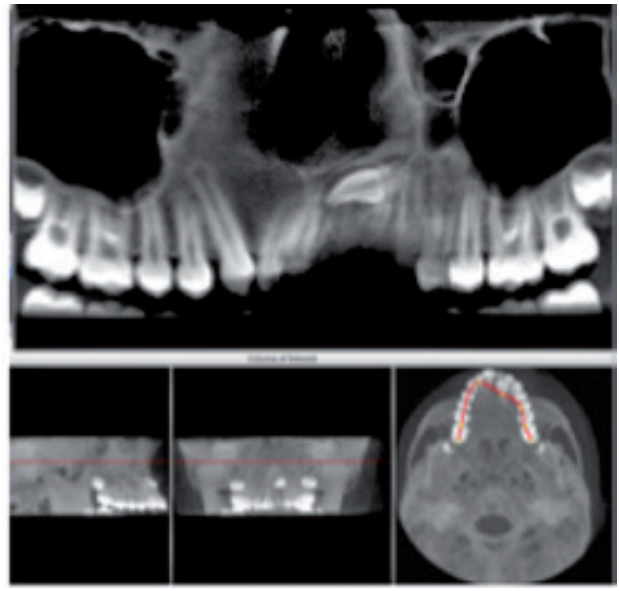

is considered to be the best diagnostic tool to assess tooth impaction $[33,34]$.

However, special measurements performed on panoramic radiographs can help us to predict the risk of canine impaction, which include: angula- 

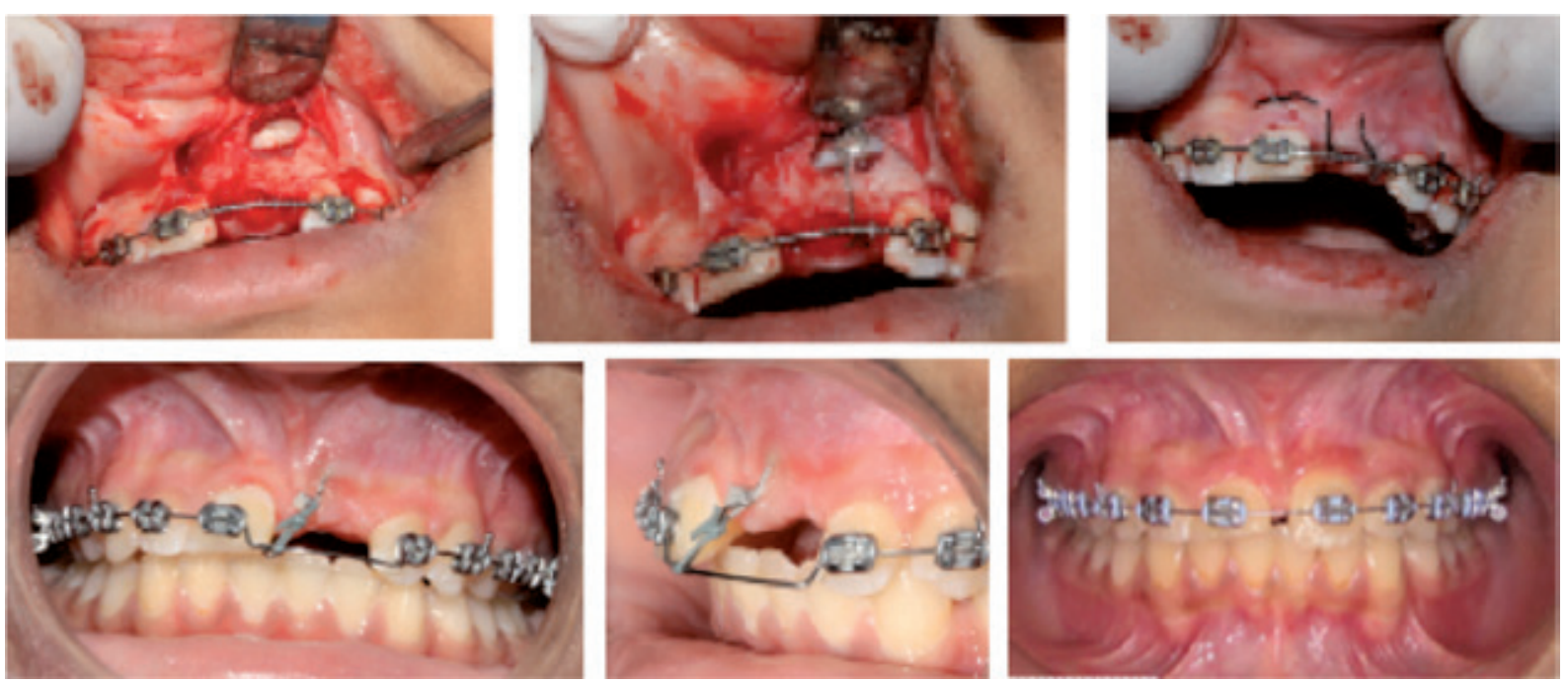

Fig. 4D. Surgical exposure (closed eruption technique) performed by Prof. Arye Shteyer

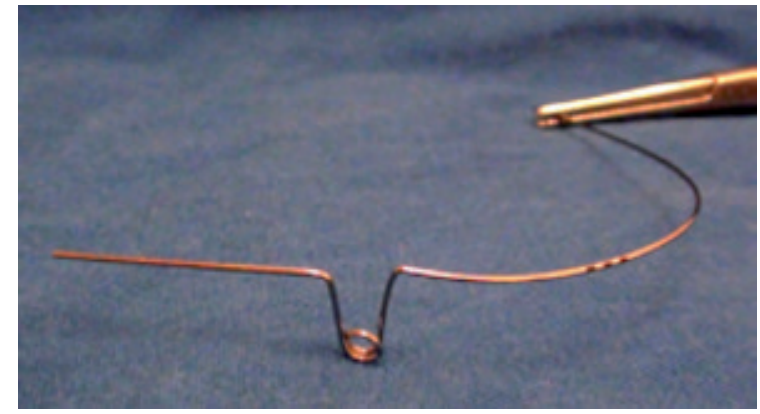

Fig. 5. The Ballista spring

tion of the long axis of the canine to the midline more than $30^{\circ}$, the position of the canine root apex antero-posteriorly above the upper first premolar region, vertical canine crown height above the cementoenamel junction but less than half way up relative to the adjacent upper incisor root or complete or even more horizontal canine overlap of the adjacent incisor root width $[21,35,36]$. When the canine cusp tip is located mesial to the long axis of the lateral incisor root, the canine can be palatally impacted. When the canine cusp tip overlays the distal half of the lateral incisor root, the risk of impaction is much lower [12].

Regarding periapical radiographs, it is advisable to obtain two or even three views of the same object, taken from slightly different angles, which can help us to distinguish between buccal and palatal canine impaction. This technique is known as a "tubeshift" or a "rule of Clark" $[1,31,37]$. The first radiograph is taken at mesial eccentric projection, the second radiograph is taken with the central beam positioned perpendicular to the alveolar process and the third one in an eccentric distal projection. If the tooth moves in the same direction as the source of X-rays, then the tooth is posi- tioned palatally. Conversely, if the tooth moves in the opposite direction, it is considered to be displaced buccally $[1,31,37]$.

If the position of an unerupted permanent upper canine is unfavorable, we may consider extraction of the deciduous canine at the age of 10 to 13 years $[1,12,16]$ or concomitant extraction of the deciduous canine and first molar [38]. According to Ericson and Kurol, $78 \%$ of ectopic canines showed normalization of the path of eruption and, later, clinically correct position at the final control after extraction of the primary canines [16], while Bonetti et al. reported favorable clinical outcomes in a group of patients having extraction of only the deciduous canine (78.6\%) compared to a group with concomitant extraction of the deciduous canine and first molar (97.3\%) [38]. Surgical exposure followed by orthodontic treatment, if needed, should be performed preferably before closure of the root apex.

\section{Interdisciplinary Treatment}

There are 3 main options in the management of impacted teeth: 1) extraction of an impacted tooth, 2) extraction of an adjacent tooth or 3) non-extraction treatment involving orthodontic space opening and surgical exposure [1].

When non-extraction treatment is performed, the orthodontic treatment is often initiated before the surgical exposure in order to align the teeth, to open the space for the impacted tooth and to enhance the natural eruption process [1]. At the surgery, any hard or soft tissue obstruction is removed and the unerupted tooth is exposed. Then, an attachment is placed on the impacted tooth, either at surgery or shortly thereafter [5]. The pres- 
ence of an orthodontist during the surgical exposure may be useful for bonding an attachment to later apply an orthodontic force in the appropriate direction and to bring the impacted tooth into the dental arch [1]. The last step is to obtain a normal position and orientation of the roots of the teeth in the alveolar process [5].

There are three main surgical techniques applied for impacted teeth: 1) the open eruption technique, 2) the apically repositioned flap and $3)$ the closed eruption technique $[1,39,40]$.

\section{Open Eruption Technique}

The open eruption technique (Fig. 2E) involves the surgical removal of a circular section of the overlying mucosa and the alveolar bone, covering the impacted tooth $[1,40]$. Afterwards, an attachment, such as an eyelet or button, can be bonded and orthodontic traction may be performed immediately [1]. The Ballista spring (Fig. 5), which is an auxiliary stainless steel archwire attached to the main archwire, may be used in order to bring the impacted tooth into the dental arch [1].

This method has both advantages and disadvantages as compared to the closed eruption technique [1]:

\section{Advantages:}

- simple and direct method,

- orthodontist's presence during surgery is not needed,

- in case of bonding failure, there is no need for a second surgical exposure.

\section{Disadvantages:}

- can result in poorer periodontal outcome,

- increased risk of infection,

- greater discomfort to the patient,

- more extensive removal of alveolar bone,

- bad taste and breath in the mouth,

- risk of closure of the exposure,

- increased bonding failure,

- additional visits to change the surgical dressing.

\section{Apically Repositioned Flap}

The apically repositioned flap is a modification of the open exposure technique. It includes the raising of a labial flap, including the attached gingiva, which is taken from the crest of the alveolar ridge and relocated higher up, and then is followed by suturing it on the buccal side of the crown of the newly exposed tooth. The main advantage of this method is the improved periodontal outcome compared to the open eruption technique by ensuring that the attached gingiva covers the labial aspect of the erupted tooth [41]. This method is well-known and generally accepted in the periodontal management of buccally displaced teeth [41]. The apically repositioned flap is performed when the tooth is located mesio-distally fairly close to its final position and a bulging of the oral mucosa appears at its junction with the attached gingiva [1].

The main advantages and disadvantages of this method may include [1]:

\section{Advantages:}

- good access for attachment bonding,

- faster eruption,

- easy follow-up.

Disadvantages:

- unfavorable gingival contour.

\section{Closed Eruption Technique (Primary Full Flap Closure)}

The closed eruption technique (Fig. 2D, 3D, 4D) involves bonding an attachment at the time of the exposure. The tissues are fully replaced and sutured to their former places, to re-cover the impacted tooth [1]. In a case when a canine is very high up and following the raising of a palatal flap, the canine will be revealed together with the thin bone covering the palatal aspect of the roots of the adjacent teeth. Below and distally to the canine is the vertical wall of the alveolar process. Bonding of the eyelet attachment is performed in the usual manner on the palatal side of the tooth $[1,41]$.

The main advantages and disadvantages of this method include [1]:

Advantages:

- fast healing,

- less discomfort,

- good postoperative homeostasis,

- less intense functional disturbances,

- less extensive removal of alveolar bone,

- possibility of an immediate traction,

- applicable close to resorbing root.

\section{Disadvantages:}

- presence of an orthodontist may be needed during the surgery,

- in case of a bonding failure, re-exposure is needed. 


\section{Complications}

The most frequent complications associated with untreated impacted teeth include [1]:

1) morbidity of the deciduous predecessor and migration of the adjacent teeth,

2) development of a dental cyst,

3) resorption of a crown of an impacted tooth,

4) resorption of the roots of adjacent teeth,

5) ankyloses,

6) infraocclusion,

7) pain and/or discharge (related to infected cysts, tumors),
8) displacement of the adjacent teeth and shortening of the dental arch.

\section{Summary}

The etiology of tooth impaction is multifactorial. Patients with impacted teeth are often referred for orthodontic help by general dentists. Their treatment is challenging and requires an interdisciplinary approach, however early detection of tooth impaction can prevent many unwanted complications by instituting preventive measures.

Acknowledgments. We would like to express our gratitude to Prof. Adrian Becker, Clinical Associate Professor Emeritus at the Department of Orthodontics, Hebrew University - Hadassah School of Dental Medicine, Jerusalem, Israel, whose assistance in critical reading and improving this manuscript is greatly appreciated.

\section{References:}

[1] Becker A: Orthodontic treatment of impacted teeth. Wiley-Blackwell 2012, $3^{\text {rd }}$ ed.

[2] Goel A, Loomba A, Goel P, Sharma N: Interdisciplinary approach to palatally impacted canine. Natl J Maxillofac Surg 2010, 1, 53-57.

[3] Chu FCS, Li TKL, Lui VKB, Newsome PRH, Chow RLK, Cheung LK: Prevalence of impacted teeth and associated pathologies - a radiographic study of the Hong Kong Chinese population. Hong Kong Med J 2003, 9, $158-163$.

[4] Hattab FN, Rawashdeh MA, Fahmy MS: Impaction status of third molars in Jordanian students. Oral Surg Oral Med Oral Pathol Oral Radiol Endod 1995, 79, 24-29.

[5] Becker A: Early treatment for impacted maxillary incisors. Am J Orthod Dentofacial Orthop 2002, 121, 586-587.

[6] Dachi SF, Howell FV: A survey of 3874 routine full-mouth radiographs. II. A study of impacted teeth. Oral Surg Oral Med Oral Pathol 1961, 14, 1165-1169.

[7] Grover PS, Lorton L: The incidence of unerupted permanent teeth and related clinical cases. Oral Surg Oral Med Oral Pathol 1985, 59, 420-425.

[8] Hashemipour MA, Tahmasbi-Arashlow M, Fahimi-Hanzaei F: Incidence of impacted mandibular and maxillary third molars: A radiographic study in a Southeast Iran population. Med Oral Patol Oral Cir Bucal 2013, 18, 140-145.

[9] Kaya GS, Aslan M, Ömezli MM, Dayi E: Some morphological features related to mandibular third molar impaction. J Clin Exp Dent 2010, 2, 12-17.

[10] Hugoson A, Kugelberg CF: The prevalence of third molars in a Swedish population. An epidemiological study. Community Dent Health 1988, 5, 121-138.

[11] Aydin U, Yilmaz HH, Yildirim D: Incidence of canine impaction and transmigration in a patient population. Dentomaxillofac Radiol 2004, 33, 164-169.

[12] Shapira Y, Kuftinec MM: Early diagnosis and interception of potential maxillary canine impaction. J Am Dent Assoc 1998, 129, 1450-1454.

[13] Gaulis R, Joho JP: Parodonte marginal de canines su-perieures incluses: Evaluation suite a differentes methods d'acces chimrgical et de systeme orthodontique. Rev Mens Suisse Odontostomatol 1978, 88, 1249-1261.

[14] Fournier A, Tourcotte J, Bernard C: Orthodontic considerations in the treatment of maxillary impacted canines. Am J Orthod Dentofacial Orthop 1982, 81, 236-239.

[15] Jacoby H: The etiology of maxillary canine impactions. Am J Orthod 1983, 84, 125-132.

[16] Ericson S, Kurol J: Early treatment of palatally erupting maxillary canines by extraction of the primary canines. Eur J Orthod 1988, 10, 283-295.

[17] Becker A, Smith P, Behar R: The incidence of anomalous lateral incisors in relation to palatally displaced cuspids. Angle Orthod 1981, 51, 24-29.

[18] Oliver RG, Mannion JE, Robinson JM: Morphology of the maxillary lateral incisor in cases of unilateral impaction of the maxillary canine. Br J Orthod 1989, 16, 9-16.

[19] Mac Phee CG: The incidence of erupted supernumerary teeth in consecutive series of 4000 school children. Br Dent J 1935, 58, 59-60.

[20] Brook AH: Dental anomalies of number, form and size: Their prevalence in British schoolchildren. J Int Assoc Dent Child 1974, 5, 37-53.

[21] Power SM, Short MB: An investigation into the response of palatally displaced canines to the removal of deciduous canines and an assessment of factors contributing to a favourable eruption. Br J Orthod 1993, 20, 215-223.

[22] Peterson LJ: Principles of management of impacted teeth. In Contemporary oral and maxillofacial surgery. Edited by Peterson LJ, Ellis EIII, Hupp JR, Tucker MR. St Louis: CV Mosby 1988, 223-256. 
[23] Ebbert S, Sangiorgio M: Facing the dreaded third molar. Prevention 1991, 43, 108-110.

[24] Peck S, Peck L, Kataja M: The palatally displaced canine as a dental anomaly of genetic origin. Angle Orthod 1994, 64, 249-256.

[25] Bjerklin K, Kurol J, Valentin J: Ectopic eruption of maxillary first permanent molars and association with other tooth and developmental disturbances. Eur J Orthod 1992, 14, 369-375.

[26] Miller BH: The influence of congenitally missing teeth on the eruption of the upper canine. Dent Pract Dent Rec 1963, 13, 497-504.

[27] Bass TB: Observations on the misplaced upper canine tooth. Dent Pract Dent Rec 1967, 18, 25-33.

[28] Baccetti T: A controlled study of associated dental anomalies. Angle Orthod 1998, 68, 267-274.

[29] Brin I, Becker A, Shalhav M: Position of the maxillary permanent canine in relation to anomalous or missing lateral incisors: A population study. Eur J Orthod 1986, 8, 12-16.

[30] Gregg TA, Kinirons MJ: The effect of the position and orientation of unerupted premaxillary supernumerary teeth on eruption and displacement of permanent incisors. Int J PaediatDent 1991, 1, 3-7.

[31] Bourzgui F, Sebbar M, Abidine Z, Bantahar Z: Management of dental impaction in Bourzgui F. Orthodontics - Basic aspects and Clinical Conciserations. InTech 2012, 219-247.

[32] Ericson S, Kurol J: Radiographic examination of ectopically erupting maxillary canines. Am J Orthod Dentofacial Orthop 1987, 91, 483-492.

[33] Chaushu S, Kaczor-Urbanowicz K, Zadurska M, Becker A: Predisposing factors for severe incisor root resorption associated with impacted maxillary canines. Am J Orthod Dentofacial Orthop 2015, 147, 52-60.

[34] Walker L, Enciso R, Mah J: Three-dimensional localization of maxillary canines with cone-beam computed tomography. Am J Orthod Dentofacial Orthop 2005, 128, 418-423.

[35] Wardford JH Jr, Grandhi RK, Tira DE: Prediction of maxillary canine impaction using sectors and angular measurement. Am J Orthod Dentofacial Orthop 2003, 124, 651-655.

[36] Stivaros N, Mandall NA: Radiographic factors affecting the management of impacted upper permanent canines. J Orthod 2000, 27, 169-173.

[37] Clarck CA: A method of ascertaining the relative position of unerupted teeth by means of film radiographs. Proc Roy Soc Med (Sec Odont) 1910, 3, 87-90.

[38] Bonetti GA, Zanarini M, Parenti SI, Marini I, Gatto MR: Preventive treatment of ectopically erupting maxillary permanent canines by extraction of deciduous canines and first molars: A randomized clinical trial. Am J Orthod Dentofacial Orthop 2011, 139, 316-323.

[39] Chaushu S, Dykstein N, Ben-Bassat Y, Becker A: Periodontal status of impacted maxillary incisors uncovered by two different surgical techniques. J Oral Maxillofac Surg 2009, 67, 120-124.

[40] Kokich VG: Surgical and orthodontic management of impacted maxillary canines. Am J Orthod Dentofacial Orthop 2004, 126, 278-283.

[41] Vanarsdall RL, Corn HL: Soft-tissue management of labially positioned unerupted teeth. Am J Orthod 1977, 72, 53-64.

\section{Address for correspondence:}

Karolina Kaczor-Urbanowicz

Department of Orthodontics

Hadassah School of Dental Medicine

Hebrew University

P.O. Box 12272

Jerusalem 91120, Israel

Tel. +972524213680

E-mail: karolina.kaczor@wp.pl

Conflict of interest: None declared

Received: 6.02 .2015

Revised: 22.02.2015

Accepted: 23.03.2015 